\title{
Acoustic Performance of Inlet Suppressors on an Engine Generating a Single Mode
}

L. J. Heidelberg, E. J. Rice, and L. Homyak Lewis Research Ceriter Cleveland, Ohio

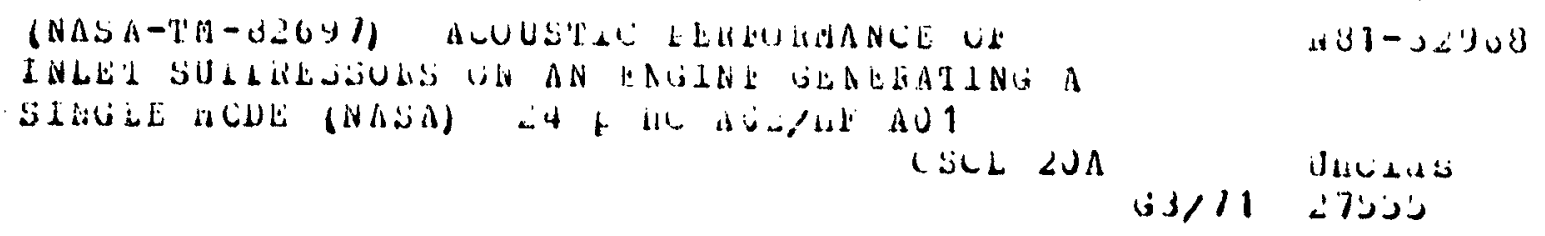

- . Ired for the

Seventh Aeroacoustics Conference.

sponsored by the American Institute-of Aeronautics and Astronautics

Palo Alto, California, October 5-7, 1981
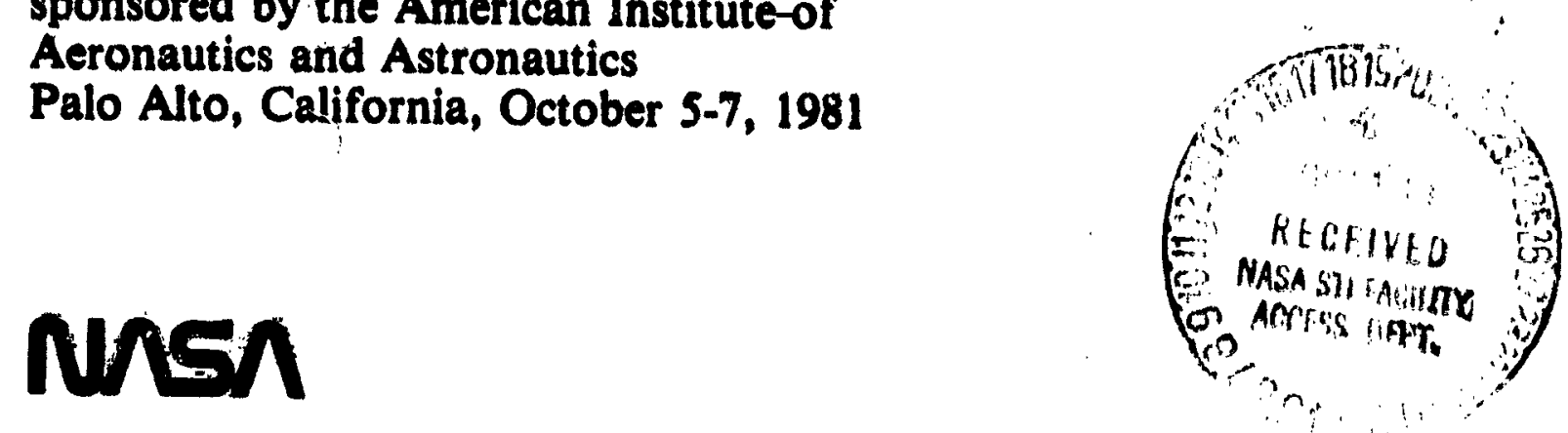


\section{ACOUSTIC PERFORMANCE OF INLET SUPPRESSORS}

IN AN ENGINE GENERAIING A SINGLL. MOUE

by L. J. Heidelberg. E. J. Rice and L. Homyak

National Aeromatics and Space Administration

Lewis Research center

Cleveland, Onio 44135

\section{Austract}

As part of a program to evaluate an inlet suppressor design metnod based on mode cutoff ratio, three single degree of freedoin liners with different open area ratio tace sheet.s were designed for a single spillnilly inode. This mode was generated by placing 41 rods in front of tile 28 olade fan of a JTLD turbotan engine. At the liner Jesign this near cutotf mode has a theoretical maximuin attenuation of nearly $200 \mathrm{~dB}$ per L/D. The data show even higher attenuations at the design condition than predicted by the theory fur dissipation of a single mode within the liner. This additional attenuation is large for high open area ratios and should be accounted for in the theory. The data snows the additional attenuation to be illversly proportional to acoustic resistance. It was thougnt that the additional attenuation could be caused oy reflection and modal scattering at the nard to soft wall interface. A reflection model was developed, and then modified to $i$ it the data. This model was checked against independent (multiple pure tone) data with good agreement.

\section{Introduction}

Fan noise produced by all dircraft engine has a spinning mode structure while propagating within the inlet or dit ducts. These spinning modes must be considered in the design of an effective suppressur. 1-3 A theoretical uesign method based on mode cutoff ratio is presented in Ref. 4. This method and the general problem of designing and evaluating inlet suppressurs from suurce to far-field is based upon each element of the problem being dependent upon the mode cutoff ratio. This dependence upon cutoff ratio nas been reported fur maximum possible attenuation, 4 opt imum impedance, 5 duct termination reflection, 0 and moval density function.'

The above concepts were evaluated on a YFlu2 engine botn qualitatively and quantitatively using the mult inodal sound source due to fan turbulence interaction. These evaluations of the design metnods and theuries were extremely demlanding and were limited by the source energy being distributed allong all possivle propagations inodes.

In this investigation, a J[1b0 engine was modified to produce a tan lone controlled by a single mode that coula be used to validate the design lneory and theoretical suppressor performance described in Rets. 4 to $y$. ro the best of the authors' knowledge, this is the first time that a controlled known single mode has been used with an engine or tan to evaluate suppressors. The single mode is gelleraled by placillg 41 equally spaced rods ill front of the $28 \mathrm{blade} t \mathrm{dn}$ as shown in Fig. 1. These rods produce a blade 
Passing frequency (Bsp) tone at only one mode with circunterentidal oraer III $\Rightarrow 13$ and the lowest radial oruer $\mu \rightarrow U$ at fan speods from ontod to

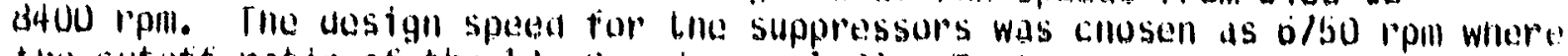
tilie cutotf ratio of tho 13, 0 mode was 1. (13. Tests were conducted at the destỵl speed as well as lligher speeds illcluding a supersomic tall tip speed. The suppressor theory. used to compare witn tho data, contaills only tilo.

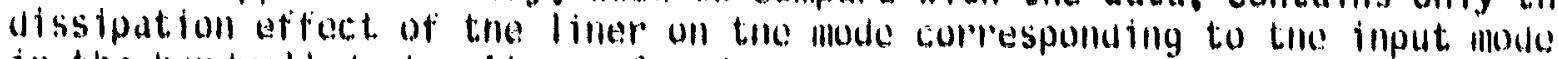
ill the hardwall duct. It was found llecessary to accounl fur duditional altenuation doe to reflection or modal scattering at the nardwall-itiner interface. A model was derived to account fur this effect.

\section{symbuls.}

A

(B)

c

1)

$\Delta$ dib

$\Delta u B_{11}$

i

kXH

kxs

L

Mu

Iii

$R$

$R R^{*}$

$R_{g}$

$n$

$\theta$

$\theta_{111}$

$\mu$

$\varepsilon_{H}$

$\xi_{s}$

a

"ill

x

deditional attenuation above liner dissipation, $d B$

blade passage frequency. $\mathrm{Hz}$

speed of sound, $\mathrm{ll} / \mathrm{sec}$

circular duct diameter, in ( $f t)$

sound at tenuation, decibels

maximum pussiole sound power attenuation, decivels

Prequency, $\mathrm{Hz}$

dimensionless axial wave number for spinning mode in hard wall duct (see Eq. y)

Jimensionless axial wave number for spinning mode in saft wall auct length of acoustic treatiment. In ( $f t$ )

axial steady flow Mach number, free-strean unitorm value

spinning mode lobe number (circunterential order)

pressure reflection coefticient

reflected acoustic power, ab

eigenvalue for circular hardwalled duct or asolute value of cont plex eigenvalue for softwall duct

frequency pardmeter. $n=\mathrm{f0} / \mathrm{c}$

specific acoustic resistance

optimum specific acoustic resistance

radial mode order index

nardwall cutoft ratio, $E_{H}=$

$$
\frac{n n}{k_{g} \sqrt{\left(1-M_{0}^{2}\right)}}
$$

suftwall mode cututt ratio, $\xi_{s}=$

$$
k_{y} \sqrt{\left(1-M_{0}^{?}\right) \cos 2 \phi}
$$

liner open area ratio

optimum open area ratio

pliase of complex eigenvalue, degrees

specific acoustic reactance 
Engine ari Inlet

The JT150-1 engine is a two-spool turoofan engine with a noininal 3.3 The JT15D-1 engine is a two-s of y7yo $\mathrm{N}(2.200$ lb). The fan is $53.3 \mathrm{cin}$
bypass ratio, and a rated thrust of
$(21$ in.) in diameter, and has 28 blades with ob exit guide vanes (stator). The blade to vane number ratio for this tan results in a cutoff rotor-stator interaction tone. More details for this engine are presented in Ref. 10_

The inlet used in this investigation is shown in Fig. 1 . This inlet has a constant $53.3 \mathrm{~cm}(21 \mathrm{in.})$ diameter and is fitted to a bellinouth wnich in turn

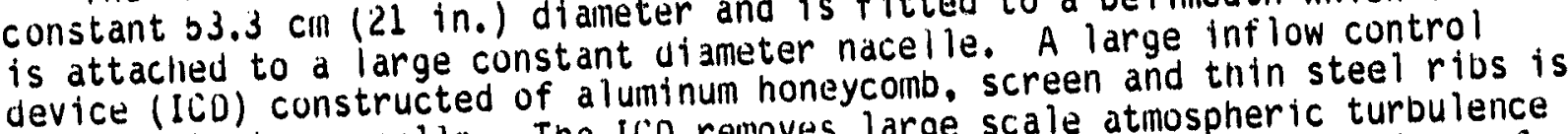
attached to the nacelle. The ICD removes large scale atmospheric turbulence and thus greatly reduces the BPF tone that results from the interactions of tile fan witn this turbulence. 10 The ICD was used here to further insure that only a single mode BPF tone is produced.

A spool piece with 41 equally spaced radial rods was attached to the engine front flange. The wakes of these rods interact with tlle 28 fan blades to produce a BPF tone with 13 circumferential lobes. At $f$ an speeds between 6400 and 8400 rpm only the lowest radial order mocle can propagate. A more complete description of the fan-rod interaction tone is presented in Ref. 11.

The single degree of freedom, SDUF type acoustic treatment was placed just up stream of the rod section of the inlet. This suppressor section is replaceable so that different treatment designs can be tested.

\section{Suppressor Uesign}

The acoustic liners were designed to heavily attenuate the single mode produced by the interation of the inlet rods and the engine $f$ an. This mode is the lowest radial of the thirteen lobed circuinferential pattern ( $m=13$, $\mu=0)$. Maximum attenuation was sought for tnis mode at the blade passage frequency of $3150 \mathrm{~Hz}$. Other parameters pertinent to the design were average duct Mach number (Mo) of -0.147 , duct diameter of $53.3 \mathrm{cin}$ ( $21 \mathrm{in.}$ ), and boundary layer thickness (1/7th power) of $0.53 \mathrm{~cm}(0.21 \mathrm{in.})$ based upon an estimate made froin velocity measurements.

ine optimum impedance was calculated using the sound propagation theory of Ref. 12 and the optimization procedure of Ref. 13. The theory consiaers the propagation of spinning modes in an acoustically treated semi-infinite cylinurical duct with a steady flow. The flow is assumed uniform except near the wall where a $1 / 7 \mathrm{tn}$ power boundary layer (with a linear profile at the wall) is merged with the uniforill ilow.

rine impedance model used to define the suppressor construction (perforated plate bunded to noneycoind) can ve tound in Ref. 8 . The acuustic resistance model is a slight modification of the model of Ref. 14, and assumes that stedy grazing flow effects dominate the perforated plate acuustic resistance (sound amplitude effect neglected).

The results of the liner optimization calculations can be found in Table 1. The values in the midule culumn. witn a pertorated plate open area ratio of $b$ percent, describe the estimated optimum liner. It should be noted that no accounting of the inevitable perforated plate nole blockage (when 
Homifed to honeycumb) was made. Also because of uncertainties in lno acoustic

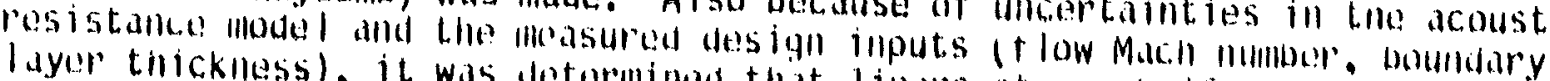
optimum loner ros iotance wouldored that liners at one-llalf and doub te the

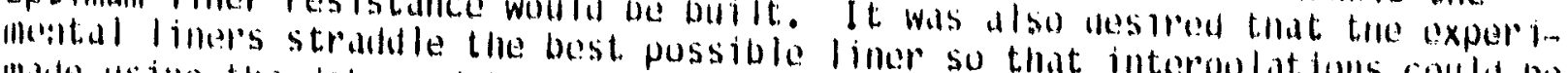
Illde using the data and the tineressible liner so that interpolat folls could be alld 8.9 porcent wale built. Note thus two liners with open alleds of r.b

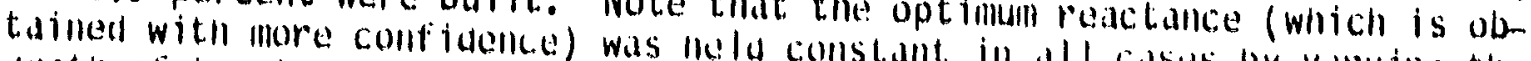
aepth of the treatment.

The lincuretical calculations for the optimum liner showed thit the maximum pussible attenuation (due to dissipation only in the liner) was sulb $=-198$ all very shomt liners shown (L $=0$ large expected athenuation suggested that the tul measurements of at $(L=6.3$ in., Io cill) must be used to obtain moaningline unprecedented attenuations. As will ve seen in a later section, due to covered with tape so that the attained, half of this length had to be balld lloise: floor.

\section{Fest Facility}

The tests were performed at the Lewis Vertical Lift Facility. This facility is an outdoor test stand sneltered oy a service building which was soved away on tracks before testing. Tie area beneath the engine out to and engine was mounted $2.9 \mathrm{~m}$ (y.5 ft) or b.4 was paved witn concrete. The lmis relatively nign position was or $\mathbf{3 . 4}$ tall dianleters avove the ground. the inlet flow. The engine exhaust was co mmilmize ground plane effects on press att tan and jet nojse. A photouraplofted to a large muffler to supis sllown ill Fig. $\therefore$.

\section{Acoustic Instrumentation and processing}

Far-field noise measurements were made with microphones on a $24.4 \mathrm{~m}$ (Bu til) radius arc centered on the engine inlet. The microphomes were positioned at $10^{\circ}$ intervals from $10^{\circ}$ to $120^{\circ}$ from the inlet axis. The $1.25 \mathrm{col}$ composition hard bodrds at ground lavel and on ol con $(L+l)$ squale

The micropllone signals were recondev and pointed at the engine inlet. on a spectrum allalyzer. The onte-thirded onl mantetic tape and tilen processed a 30.6 III (100 tt) free-field radial distactaveband results were corrected to and relative humidity (by" $F$ and 70 istalce dnd standard-ildy temperature appliea to the ground micropmone datareent, respectively). The correction -0.0 ab at all trequencies up to $20 \mathrm{kHz}$.

lyzer. Narrow band resultse processed on a separate 300 line spectrum alla"ds measured" torm.

rest Procedure

Fur all tests, data were obtained at the following corrected $t$ an

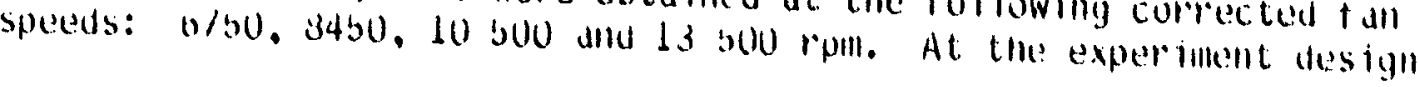


speed of b7an rom a second set of dala was measurea to improve accuracy. A baseline hard wall case was always run the sallo day to timprove the quality of the attenuation results. Tho llarawall case was aitainod ay covoring tile: acoustic liner with aluminuin tape. After the baseline was obtained. tille tape was romoved in two stages to obtaill illosurements for troatment longths of $L / 0$ of $0.1 ! 5$ and 0.3 . Data was only recorded when the antbient wind was less t.an $18.3 \mathrm{~km} / \mathrm{lll}(10 \mathrm{mmph})$.

\section{Results and Discussion}

The data is presented in both one-third-octave-band and llarrow band form. A $2 \mathrm{~b}-\mathrm{Hz}$ vandwidth narrowband and lys is was used where the oroadband lloise fluor affects the accuracy of the vile-third-octave band tune data. All one-tnird-octave-band data has been corrected to standard-day, free$f$ ielu at 30.6 il (100 ft). Narrow-band data nas nut been currected, and is presented "ds measured".

\section{Baseline Inlet Noise}

The inlet nuise of the unsuppressed engille with the 41 rods installed is sllowll by the four une-third-octave power spectra ill Fig. 3. The BPF is very prominent at all four speeds. At the highest speed (tip relative Mach nunber of 1.2). the multiple pure tones. Mri's are very evident between 2000 and $4000 \mathrm{~Hz}$. The dashed line represents the power spectrd for a suppressed case, the 8.9 percent upen area liller with all $L / 0$ ot $0.1 \mathrm{~b}$. TIIIs gives an indication of where the liner was effective. At design speed the BPF tone is no longer evident in the spectrum. The only other place where there is a great deal of suppression is at 13 bou rpin at the MPT frequencies. The reason for this bellavior will be discussed later after tone directivities and cutoff ratios are presented. Although the suppressions at the other speeds and frequencies are much lower, they are not insignificant, 10 to 20 dB per unit $L / 0$.

The onc-tnirductave BPF tone directivities for all the fan speeds are sllown in fig. 4. At a tall speed of o/bu rpill the $(13,0)$ mode is just cut on with a cutoff ratio of 1.03. All higher order radial modes are cutoff. The peak in the directivity plot is at $00^{\circ}$ as would be expected for a mode near cutoft.1 As the tan speed increases the cutofif ratio of the $(13,0)$ mode increases and the directivity curve peaks at far fiela dikgles closer to the inlet axis. This effect can be masked (as in Fig. 4(d)) when higher order radial modes being propagating ( 10 bou rpan and above) alld the directivity pattern is a result of several modes of different cutofi ratio. A more complete discussion of tile BPF directivity of this tall with the at rous is presented in Ref. 11.

rnese directivity patterns are important since they can indicate the modes and corresponding cutoff ratios that are present. III Larn controls line maximum possiole attenuation and optimlim inpedance for a suppressor. 4 
The sound power attenuation curves shown in Fig. S give an overview of where attenuation was olltained in terms of trequency and speod. lhe curves

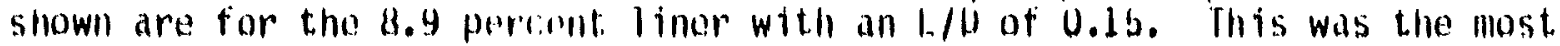
effective limer. The other liners yielded similar curves but with lower peak lavels. Excopt at the design speed the bif attenuation is of the order

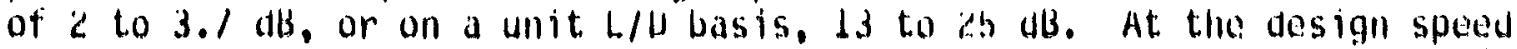
16.5 dB of BPF power reduction was obtained, or 83 dis per unit $L / 4$. llits number is in crror on the low side due to the dominant contribution of the broadband noise to the BPF one-third-octave-band at many angles in the suppressed case.

The liners were designed for the $(13,0)$ mode at 31 so $\mathrm{Hz}$ where the cutaft ratio is 1.03. In general, it would be expected that when the cutofit ratio is higher or the frequency different than the design, lower al.tenuation would result. The maximum possible attenuation decreases very rapidly when the cutotf ratio increases trom unity. Also the optimum impedance for a given mode is a function of cutotf ratio and trequency.s for these reasons the large $B P F$ attenuation occurs only at the design speed and since the cutoff ratio increases with speed and the actual wall impedance diverges from the opt imum, the attenuation drops. This dramatic change in liner attenuation with engine speed does not occur for multimodal excitation as was observed in Ref. 8. An examination of the source noise in this investigation shows only two places where single moues exist near cutotf. Une is the design condition and the other is the MPT's at sapersonic blade tip speeds. The MPT cutott ratios vary from 1.00 to $1.0 \%$. Figure $b(d)$ shows a great deal of attenuation for these MHT's as is expected. In tact, the MPT that corresponds to the design frequency, $31 \mathrm{bO} \mathrm{Hz}$ has a cutoft ratio of 1.U3, the same as the BPF had at the design point. Ine MPT results will be discussed in more detail later in this paper.

BPF at the Uesign Point

A typical one-third-octave-band directivity plot of the BPF is shown in Fig. 0 . Here the short liner length $(L / U=U .1 b)$ produced a large reduction in tone level especially at the peak angle $\left(60^{\circ}\right)$ and larger angles. When the remaining half of the tape was removed $(L / U=0.3)$ little further reductions surred due to the presence of the broadband noise floor. Even in a $25 \mathrm{~Hz}$ bandwidth analys is the broadband floor interteres with the resuits for all LIU of 0.3 . The narrowband results for this liner (Fig. 7) indicate tone level reductions of several ab more than shown by the onethird-octave plot for the L/U of $U .1 b$. Here the narrowband ( $26 \mathrm{~Hz}$ balluwidth) tone directivity is plotted for the hardwall inlet and for the 3.9 percent open area liner at the $L / 0$ of 0.15 . The broadband noise level at the tone base is also plotted. Even with all L/U of only $0.1 \mathrm{~b}$ and a $26 \mathrm{~Hz}$ bandwioth, the broadband levels are uncomtortably close to the tone in the suppressed case. Alchough the broadband levels show a sillall reduction in leve! when compared to the tone these attenuations are significant when put on a unit L/U basis, It to 20 ab. The shape of the broadballd direstivity curve, with a peak near the dxis, indicates this source is composed of a great many modes with approximalely equal energy per mode. 0 with this 
type of modal energy distribution much lower attenuations are expected than when all the energy is concentrated in one near cutoff mode.

The directivity of the tone suppression at the destan condition for all tinree liners is shown in Fig. 8. The suppression generally increase to about io degrees then remains at nigh levels. The 2.5 percent open area liner lias about nalf the suppresston of the other two liners. The B.y percent liner appears to give somewhat better suppression than the 5.0 percent
iiner.

One way to show the effect of open area ratio on attenuation is to use the following approximate relationship fruil Ref. 15 :

$$
\Delta d B \propto \frac{\theta}{\theta}
$$

when

$$
\theta>\theta_{m}
$$

and

$$
\Delta d B=\frac{\theta}{\theta_{m}}
$$

when

$$
\theta<\theta_{m}
$$

This approximation call be put in terms of liner open area ratio by using

$$
\theta \times \frac{\left(1-0^{2}\right)}{0}
$$

This results in

$$
\Delta d B \times \frac{\left(1-\sigma_{m}^{2}\right) o}{\left(1-\sigma^{2}\right) \sigma_{m}}
$$

when

$$
0<v_{\text {III }}
$$

and

$$
\Delta u s=\frac{\left(1-\sigma^{2}\right) u_{11}}{\left(1-\sigma_{11}^{2}\right)_{0}}
$$

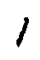




$$
\text { a }>a_{\text {In }}
$$

In Fig. $y$ attenuation is plotted agallst the above open area ratio fuikcions.

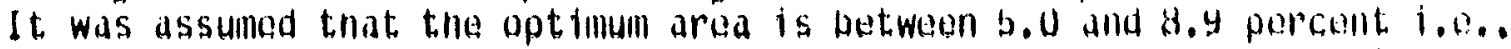
straignt lines from the origins toraugn tome 5.0 and 8.4 percent points moet at the optimum open area ratio. The average attenuation botwoen bo and $80 "$ was used as an indlcation of sound power" attenuation of tilc BPf tone at the destgn speed. Altnough the 2.5 percent data was not used fil the data fit. it falls on the line. Fitting the data through the $\mathbf{3 . 0}$ alld $8 . \$$ percent points as described above results in an optimuin open area ratio of 7.1 percent. fhis is nigher than tho dosign estillate of $\$ .0$ percent but not that far away when considuration is given to the assumptions and vartables involved. For example. an error in the houndary layer thickness used to calculate the resistance could account for all of the difference between the 5.0 and 7.1 percent. Also, the reduction of open area due to the adliesive used to bond the face slleet was not accounted for. The theoretical attenuation limit for the $(13,0)$ mode is included in rig. $y$. The data plot indicates a peak of 27.2 or 181 dis per unit L/U. This is very good ayreement witn the theoretical limit of $198 \mathrm{~dB}$ per unit L/U.

Uft-optimum liner attenuation. - As discussed in the liner design section it was not anticipated that the opt imun Iner design would truly de achieved and two extra liners were built. It is thus necessary to investigate how much acoustic dissipation migint ve expected within the suppressur for conditions uther than at the optimum. Also in spite of the large attenuations expected, it will be soler that evell nigher attenlations were obtailled from the suppressor experiments. A complete set of theoretical predictions of single mode acoustic vissipation in the liner is necessary for comparison with the experimental data.

To evaluate ofi-optimum sound attenuations in the suppressor, the approximate circular constant attenuation contour equation found in the appendix of Ref. $y$ was used. Inis correlation provides good approximation to exact suppressor calculations. The inputs used for this equation illvolve only the optimum impedance and the associated maximum possiole attenuation which were $\theta_{11}=1.1360, X_{m}=-0.50, \Delta U B_{11} / L / D=198$ respectively, the duct Mach number $M_{0}=-0.147$, and the soft-wall mode cutoff ratio $\xi_{5}=0.82 y 1$. Uue to the sillall cutoff ratio the compression of the attenuation contours due to the boundary layer can be neglected. Fur all calculations the liner reactance was assumed to be equal to the optimum value.

With the above inputs, the liner resistance can be varled from zero to infinity to generate the relationsnip shown in Fig. 10. The curve has the extremely sharp peak which is characteristic of the attenuation for a single mode as generated fur tests in this paper. For multinodal sound genteration much more flat curves will result as discussed in Ref. $y$. Note that the attenuation shown in $F i g$. 10 accounts only for principal mode dissipation within the lined duct. Any attenuation greater than these values llay be assumed to uriginate from other mechanisms such as reflection or modal scattering at the haratsoft interface of the suppressor. This assumption will be used to develop relations for these otner phenomena in a later section. 
The data is plotited in Fig. 10 for two different aptimuin resistances (open areas). In one case the r.o percent point is made to fall on the theoretical curve, which resilts in an optimum open area of 5.4 percont, and in the other case the optimum was chosen at 7.4 percent. In goneral, the data talls abovi the curve for most em that aro chosen. It seams likely. as discussed previously, that reflections and madal scattering trom the hard to sult. wall interface could cause the data to fall above tille curve. It inight be expected the larger the change in wall reststance at the intertace che laryer the rem flection and modal scattering. Since the 2.5 percent opon area liner inight bu expected to have little or no reflection tit was made to tall on the theoreti. cal attenuation curve. This resulted in the 6.0 percent liner data talling bolow the curve. It seems reasonable that the data could be higher than thes. ory expecially for the liners with higher open area ratios. It is more difficult to understand why a data point would fall bolow the curve as in the case of the b.U percent liner, when the other points are on or avove. The data points seem to fall til a more reasonable fashion whon the optinum open area is chosen at $\% .0$ percent. Here the points tall progressively higher above the curve as the open area increases. It additional at tenuation caused by the hard to sot t wall intertace is the major cause of the discrepalicy, it is important vecause of its size to accounc for it in the theory. The largest discrepancy occurs in the 8.9 percent data where 36 percent of the total attenuation may be due to mechanisins other than dissipation within the lined
duct.

If the strength of the additional attenuation above liner dissipation is plotted against the reciprocal of open area ratio (resistance) on log-log scale, a functional relation of the variables may becone evident. ih is plot was made for a range of $o_{11}$ and a straignt line resulted when $0_{m}=7.0$ percent as shown in Fig. 11. The slcpe of this line turns out to be -1.0 . This plot not only indicates that 7.0 percent open area is optimum, but al iso that at a tixed cutotf ratio and liner reactance, the additional attenuation due to the hard to soft wall interface is inversely proportional to resistance. Keflection and scattering. - The previously discussed comparison between theory and experiment for the suppression of the blade passage tone has shown that more attenuation is attained than can be explained oy simple dissipation of the principal mode within the suppressor. This suggests that additional attenuation mechanisms are operating which are not included in the suppressor theory. These many include reflection and scattering at the hard-soft interface of the suppressor. An approximate equation for the reflection effect will be derived (scattering will be neglected) to provide a hint on the grouping of the important variables and then the equation will be empirically moditied to tit the blade passage frequency attenuation data. Without further modification this equation will be used to calculate the additional attenuation of several illultiple pure tones and the results will be compared to data
in the next section.

Keflection and scattering are intimately conrected but reflection is qualitatively diffurent than dissipation. No dissipation can ve expected for nearly llard walls $(\theta \approx \infty)$ or for very soft walls $(\theta=U)$ since hard walls allow no normal flow into them and very soft walls have no acoustic resistance to grovide oissipation. Since the two extremes provide 110 dissipation peak dissipation must occur somewhere between and this is the opt imum impedance which was discussed earlier. Keflection, although expected to be zero for 
Tardwalls, is not necessarily negltgible for soft walls. There may de a monotonic increase in reflection as resistance is roducea, and the overall oplimum resistance might be expected to be slightly shifted toward a sinaller restst.m ance than would be obtatned from a disstation only tmeory.

In Ref. I6 (page 15ig) the ref lection caeffictent for a plane-wave flicident, upan a suppressor nas boen derivad. It is destred liere to abtaill an expraso slon for incident spinning modos rathon than for the special caso of a plano wave with an infintto cutafi ratio. A mage matching solution with pressure and axial veloctty matching across the hardsoft intorface (considering only a single spinning mode) providos a load torm in the solution which is analagous to that of Eq. 11.4.26 of Ref. 16. This equation is

$$
k=\frac{k_{X H}-k_{X S}}{k_{X H}+k_{X S}}
$$

where $R$ is the pressure reflection coeffictent, and $k \times H$ and $k \times s$ are time dimensionless axial wave numbers for the sptining mode in the hard and soft duct sections. Equation $\left(0^{\circ}\right)$ is accurate in the lintt for nearly hard walls. The finite mode cutoft ratio, $\xi$ is present in the axial wave nullim ber. An inspection of Eq. 11.4.20 of Ref. 16 shows indexed multiple products which represent the scattering effect of higher radial modes which is neg-
lected here.

All expansion of $E G$. (b) around nearly hard walls with the parameter

$$
\varepsilon=\frac{i \pi n}{\theta+i x}=\frac{\pi n}{\left(\theta^{2}+x^{2}\right)}
$$

considered sinall yields

$$
R=\frac{1}{1-2 \pi n k_{X H}^{2}(x+i \theta)}
$$

where

$$
k_{X H}^{2}=1-\frac{1}{\xi_{H}^{2}}
$$

and 5 is the mode cutoff ratio in the hard duct. An estimate of the reflected acoustic power is

$$
R K^{*}=\frac{1}{\left(1+2 \pi n k_{X H}^{2} x\right)^{2}+\left(2 \pi n k_{X H}^{2}\right)^{2}}
$$


and the attenuation duo to reflection is

$$
A d B_{R} \approx \operatorname{lol} \log \left(1-R R^{*}\right)
$$

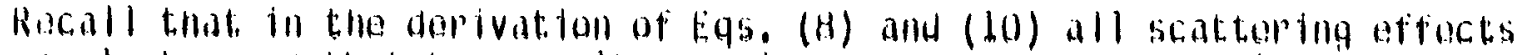

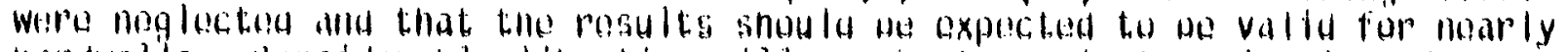

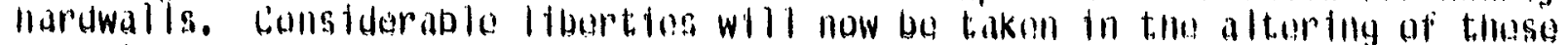

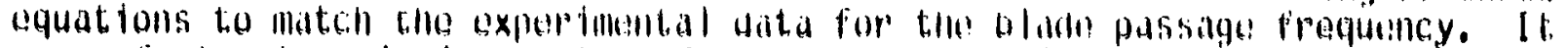
was a fortunate colncidence that for the provious blade passage tone candlo

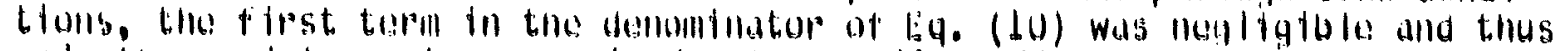
anly the resistance toril romatned. All excellont fit to bine data, as shown in

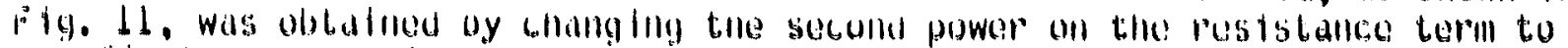
che first power. Stace the rodetalle terill was negligible no firtorilation could we obtaince on tile exponent of this teril so it was drbitrarily reduced to the first poiver lil and logy with the resistance. The empirical tinal results which must be considered speculat tve and meeding much more study are

$$
\left.R R^{*} \cdot 1+2 \pi n k_{X H}^{?}\right]_{0}^{1} \mid+2 \pi n k_{X H}^{2}
$$

It was also required that Eq. (!1) ve challged to

$$
\Delta U B_{k}=40.0 \log \left(1-R k^{*}\right)
$$

to match the level of the additional attenuation that was obtained in the experiments.

Althuagn the approach taken in this section is quite crude, perspective should be maintailled by recognizing that the correlation developed relates only to the incremental attenuation shown in Fig. 10. Most of the attenuation is accounted for by the mure soundly based liner alssipation theary. Equations (12) and (13) will be tested against other independent data ill the next sectivil.

It' l's at 13 bou rom

The attenuation of the Mipl's for each of the three test liners is shown as a function of llardwall cutorf ratio in Fig. 12 . Pinese attelluations are ubtained using narrowband data at $60^{\circ}$ and $70^{\circ}$. Some of the Mip attenuations are very large allu comparable to the BPF attenuations at the destgn speed. This is not unexpected since each MP $i$ is a single llode and has a cutoff ratio near unity. In general, the attenuacion fincreases as tile open area ratio increases and decreases as the cutoti ratio ficreases. Two sets of theoretical predicthons of the attenuation for each open area ratio liave been included in $\vec{F}$ ig. 12. The lower curve represents only the dissipation in the liner. The values used here for the acoustic resistance were calculated by setting the effective open area ratio to b/7 of the actual. This reduction is based on the results for the single mode BPF data where $0_{11}$ was showl to be 1.0 percent instead of the preatcted b.0 percent (Figs. 10 and 11 ). The upper curve in each set 
represents liner dissipation plus the additional attenuation due to roflection and modal sfattering as doveloped in the previous section of this paper and modiffed to tit the buf data (Eqs. (12) and (13)). These upper curves fit the data well although thoro is ronsiderable scatter for individual MH't's. The theoletical predictions seem valid considering thoy aro based oll Independent data. Tho largost atscropancy occurs as the culate ratio approdchos untiy. Theoretical attenuation prodictions which include mode rof loct fon and scatioring and finte? liner length should be compared to this exportimental datio.

\section{lancluding Ro!narks?}

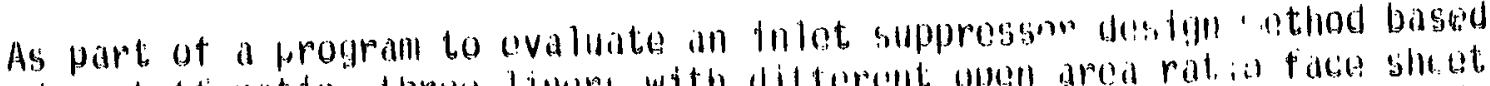

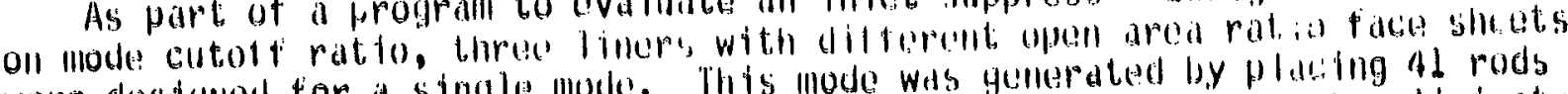

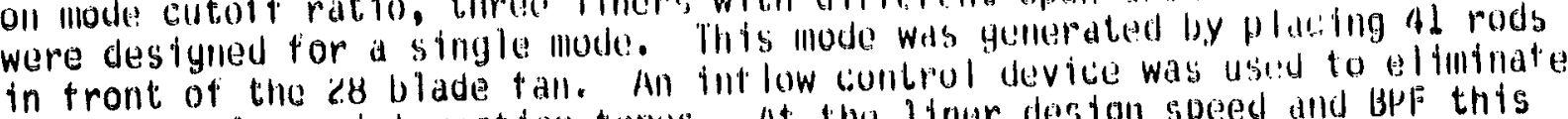
rotoraturbulence interaction tunes. At the liner destgn speed and $B P^{\circ}$ this mode $(\mathrm{m}=13, \mu \mathrm{U})$ is near cutotf. The theoretical attenualion limit for this condition is almost 200 db per unit L/U. Vata were also taken at higher speeds including a supersonic tip speed where MPl's were generated.

Extremlely high attenuations (143 dB per unit L/U) measured were at the liner design condition. Much lower but still signiticant attenuations were measured at other speeds and trequencies with one exception. Ihis $n$ e at 11 is supersonic tip speed where the MPI's had attenuations almost as larye as thi BPF attenuation at the design speed. Whell compared to the theoratical ras $c_{i b}$. ance versus attenluation curve, the data at the design convition ins hit: attenuations. This suggests attenuation mechanisms th additi to a sh pation in the lined wall. Keflection and posstbly mod. ...ing at the hard to soft wall interface was thought to be res: "sic ror the additional attenuation. The data indicated the additional biatidntion sas inversely proportional to resistance. In addition, the optimum open area ratio for liner dissipation was tound to be 7.0 percent instead of the predicted b.U percent. Error in the boundary layer thickness and not accounting for the blockage due to thi adnesive used in construction may be responsible for the difference in opt mum open area. A model tor reflection at the hard-soft interface was developed that indicated reflected power to be inversely proportional to the square of the acoustic resistance and reactance. The theoretical model was moditied to agree with the tirst power relationship of resistance found in the data. The model was then tested against other independent data (MPT's) and tound to be in good agreenent. This preliminary reflection model requires further study. For high open area ratios and near cutoff modes the retlection at the hard to soft wall intertace is a significant factor in the total attenuation.

\section{keferences}

1. Yurkovich, K., "Attenuation of Acoustic Modes in Circular and Annular Uucts in the Presence of Uniform Flow," AlAA Paper 14-bbc, June 19/4.

2. Rice, Idward J., "Spinning Mode Sound Propagation in vucts with Acoustic ireatment," NASA IN U-7Y13, May 19/b. 
3. Motsinger, R. E., Kraft, R. E., and Zwick, J. W.. "Design of Optimum Acoustic Treatment for Rectangular [ucts with Flown" ASME Paper 76 GT-113, Mar. 1976.

A. Hice, E. J.. "Inlet Noise Suppressor Design Method Based Upon the Uistribution of Acoustic Power with Mode cutoff Katio," Advances in Engineering Science, Vol. 3, NASA CP-2001, 19?6, pp. 883-894.

5. Rice, E. J., "Optimum Wall Impedance for Spinning Modes - A Correlation with Mode Cutoff Ratio," Journal of Aircraft, Vo 1. 16, Ho. 5. May 1979, pp. 336-343.

6. Rice, E. J., "Multimodal Far-Field Acoustic Radiation Pattern Using Mode Cutoff Ratio," AIAA Journal, Vol. 16, No. 9, Sept. 1978, pp. 906-911.

7. Kice, E. J. "Modal Density Function and Number of Prspagating Modes in Uucts," NASA TM X-73539, 1976.

3. He ivelberg, L. J., Rice, E. J., and Homyak, L., "Experimental Evaluation of a Spinning Mode Acoustic Treatment Uesign Concept for Aircraft Inlets," NASA TP-1013, 1980.

9. Rice, E. J. and He idelberg, L. J., "Comparison of In let Suppressor Data with Approximate Theory Based on Cutoft Ratio," AIAA Paper 80-0100, 1980.

10. Mcardle, J. G., Jones, W. L., Heidelberg, L. J., and Homyak, L., "Comparison of Several Inflow Control Devices for Flight Simulation of Fan Tone No ise. Using a JT15U-1 Engine," ALAA Paper 80-1025, June 1980.

11. Heidmann, M.F., Saule, A. V., and McArdle, J. G., "predicted and Ubserved Modal Radiation Patterns from JT15U Engine with In let Rods." Journal of Aircraft, Vol. 17, No. 7, p. 493, July 1980. (Also NASA TN-7yU74.)

12. Kice, E. J., "Spinning Mode Sound Propagation in Uucts with Acoustic Treatment and Sheared Flow," Aeroacoustics: Fan Noise and Control; Uuct Acoustics; Rotor Noise, edited by 1. R. Schwartz, H. T. Nagamasu, and W. C. Strahle, AIAA Progress in Astronautics and Aeronaut-ics, Vol. 44, American Institute of Aeronautical and Astronautics, New York, 1976, pp. 475-505. Also AIAA Paper 75-519, Mar. 1975 and NASA IN X-71672, 1975.

13. Kice, E. J., "Acoustic Liner Opt imum Impedance for Spinning Modes with Mode Cutoff Ratio as the besign Criterion," AlAA Paper 76-516, July 1976; a lso NASA IM X-73411, 1976.

14. Hersch, A. S. and Waiker, B., "Effect of Grazing Flow on the Acoustic Impedance of Helmholtz Resonators Consisting of Single and Clustered Orifices," NASA CR-3177, 1979.

15. Rice, E. J., "Attenuation of Sound in Jucts with Acoustic Treatment A Generalized Approximate Equation," NASA TW X-7183U, 1975.

16. Morse, P. M. and Feshbach, H., Methods of Theoretical Physics, Part 11 , McGraw-Hill, New York, 1 yb3. 
IAKSIE 1. - SUPPIRESSIIK IHESIGNS FOK

IIIE in $n 13,4: 0$ Mullt:

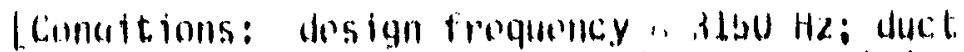
Mach Number $=-0.14 /$; duct Wtameter $=21 \mathrm{t}$. $(53.3 \mathrm{coll})$; opt imum impedunce: $\theta=1.136$, $x=-0.50 . J$

upon area, a, percent $c . b \quad b .0 \quad 8.9$

Iroatment depth, in. U.joA U.b00 0.610

Estillated resistance, $\theta \quad 2.27 \% \quad 1.130 \quad 0.633$

Estimated reactance, $x \quad-0.50 \quad-0.50 \quad-0.50$

$\begin{array}{llll}\text { Length, } L \text {, in. } & 0.3 & 0.3 & 0.3\end{array}$

aAll iacing sheets were $0.020 \mathrm{ing}(0.0 \mathrm{bl} \mathrm{cm})$ thick, perforated $3003 \mathrm{H} 14$ aluminum with punched holes of U.U5U in. $(0.127 \mathrm{~cm})$ dianeter. 


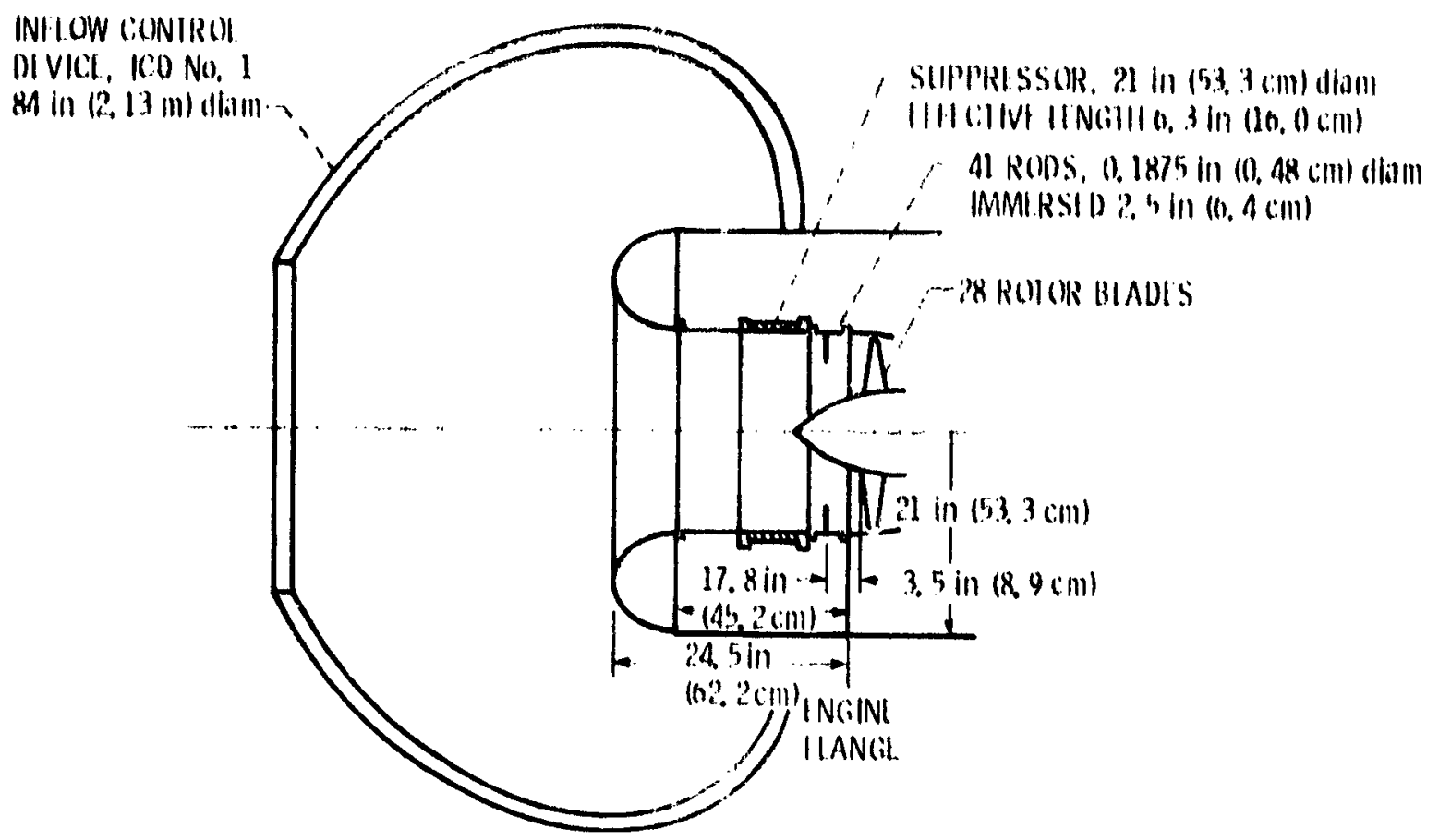

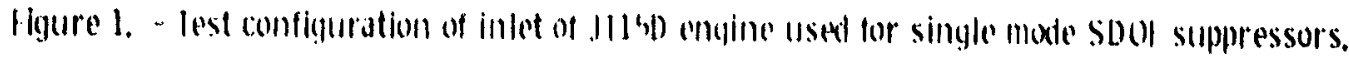

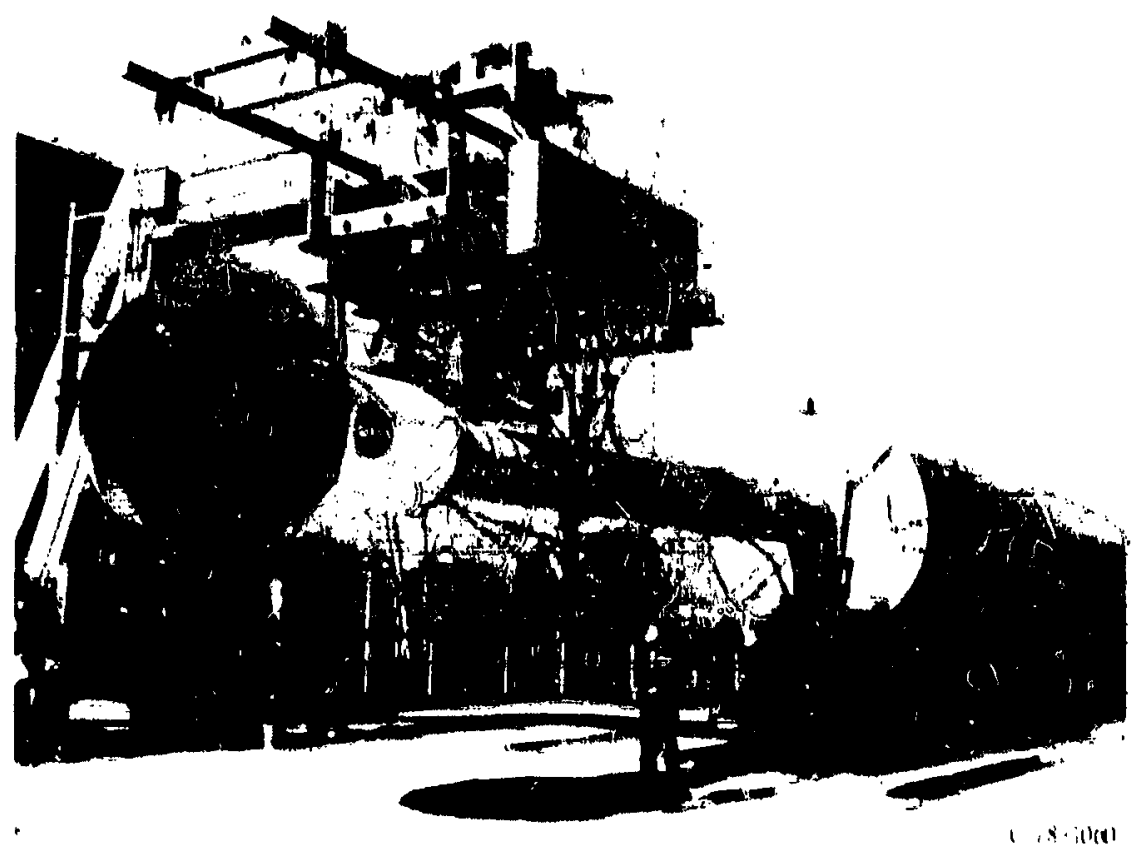

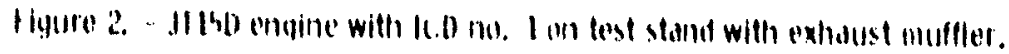



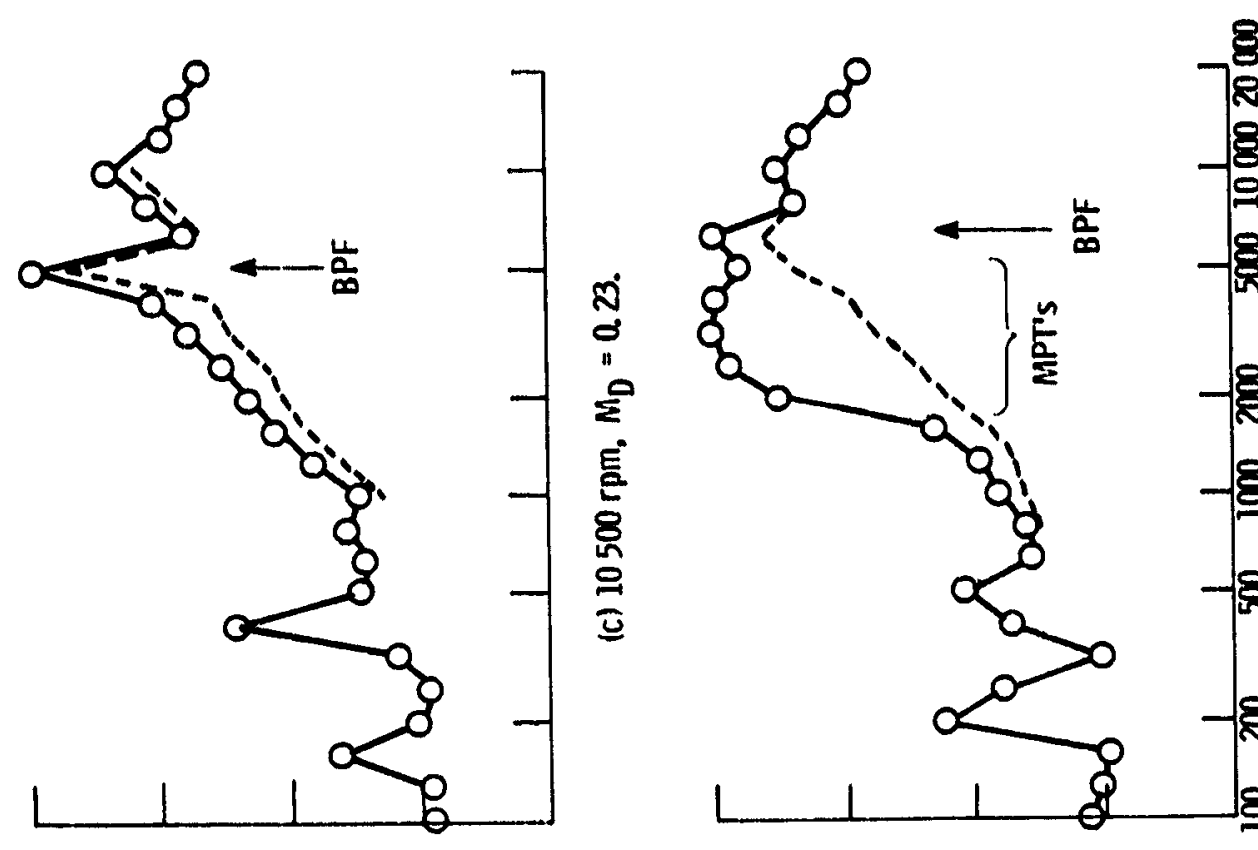

$-\begin{aligned} & 8 \\ & 8 \\ & 8 \\ & 8 \\ & 0 \\ & 0 \\ & 8\end{aligned}$

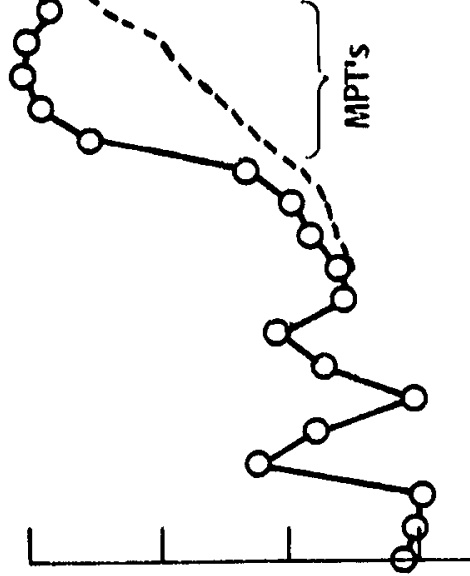

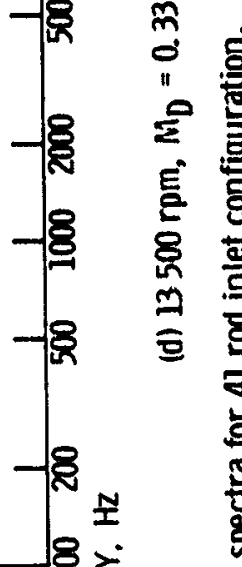
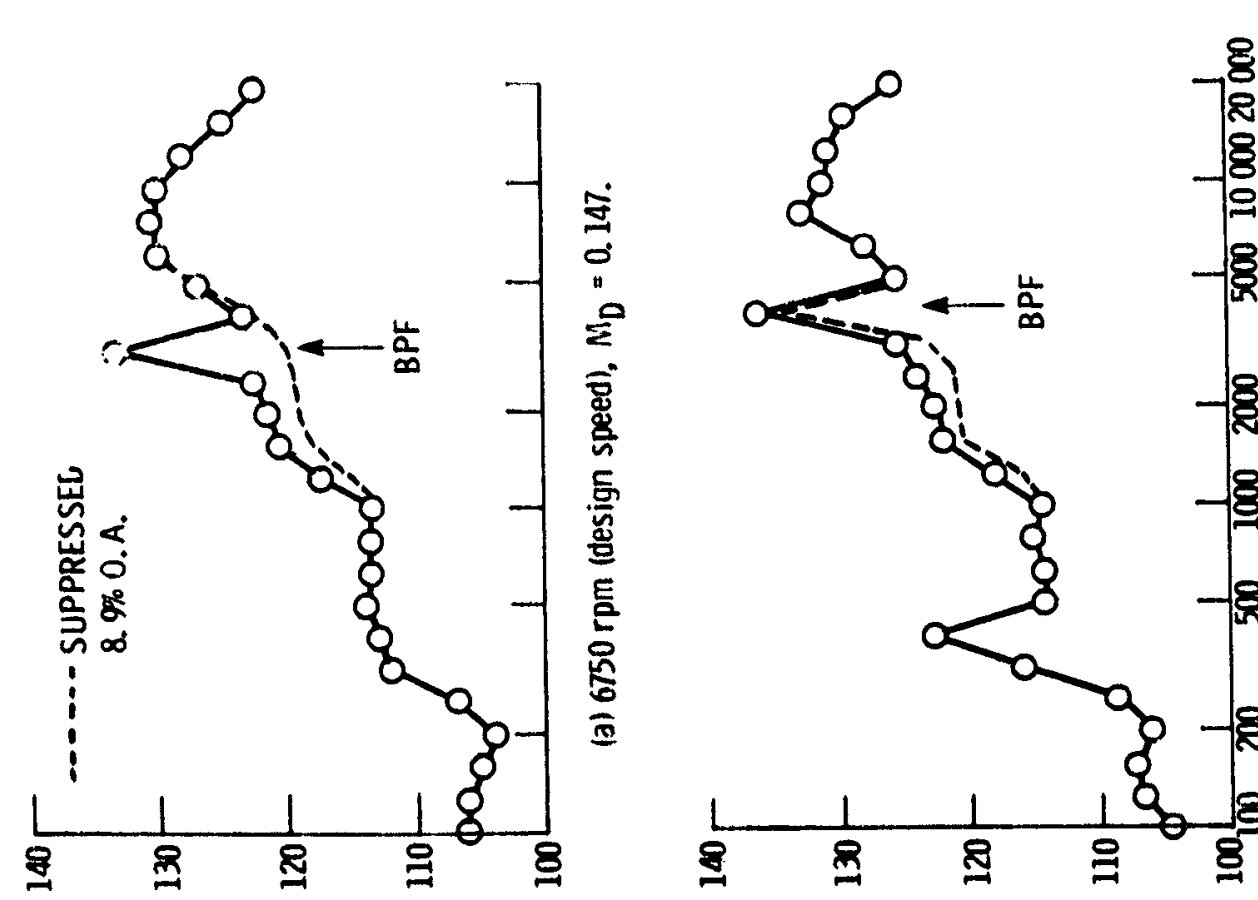

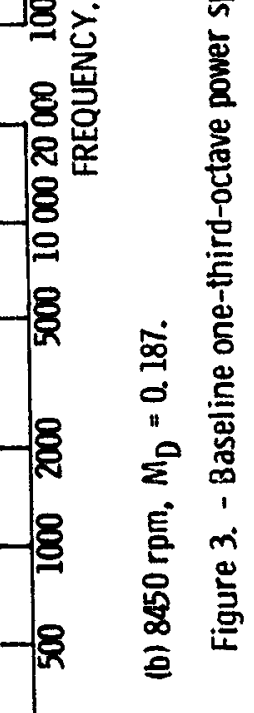

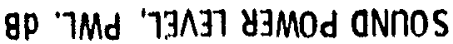




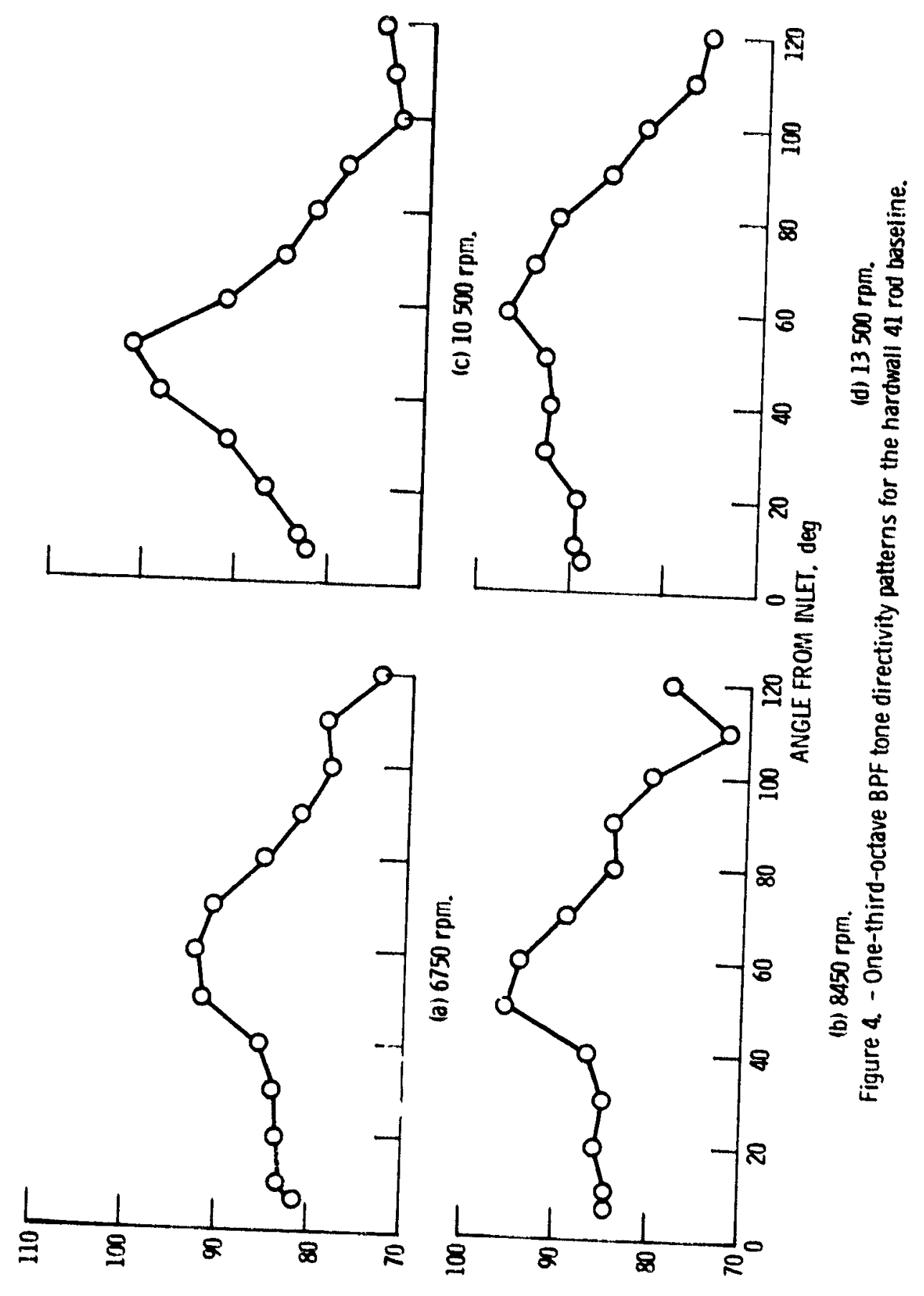

8p '13nj1 jynssyad onios 


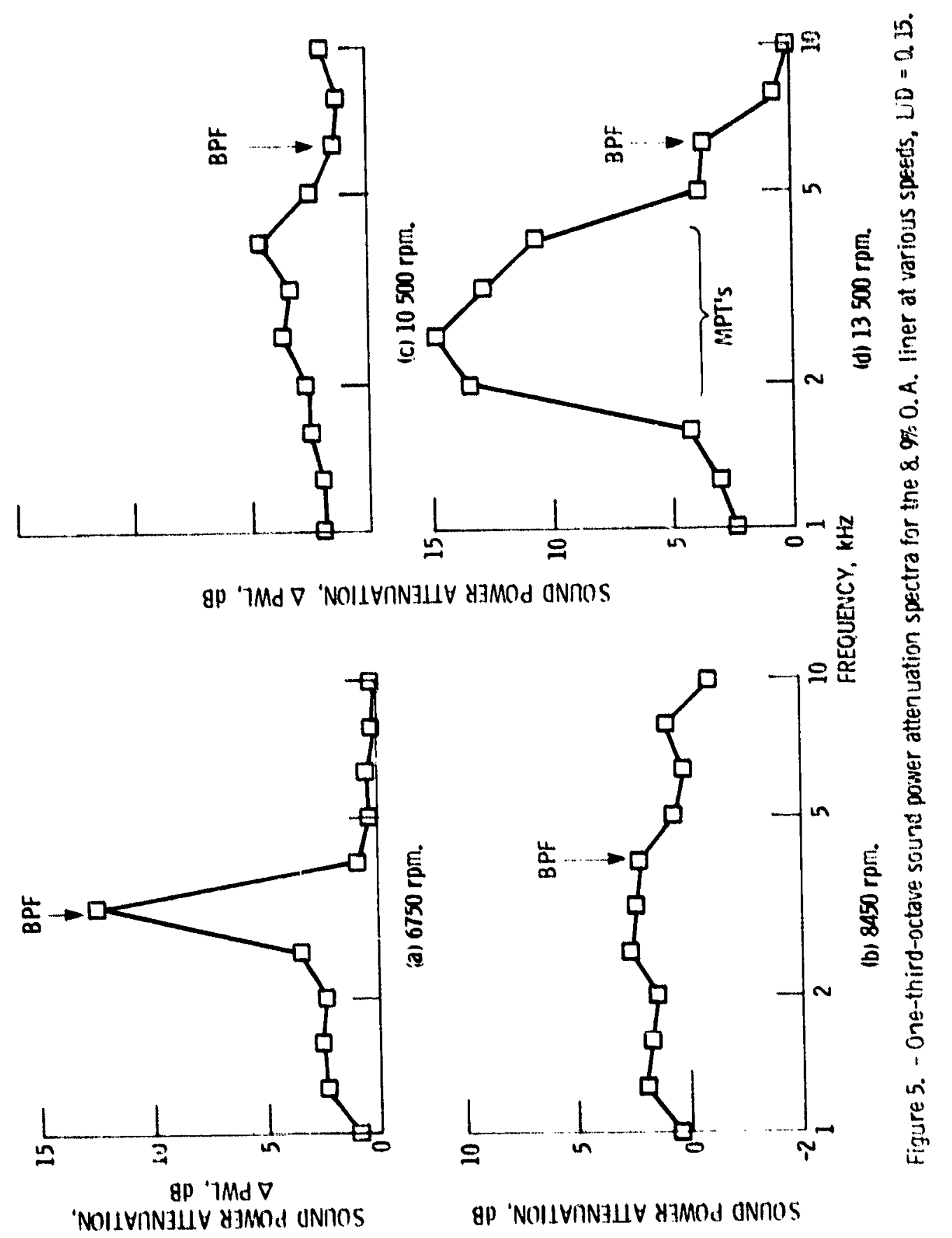




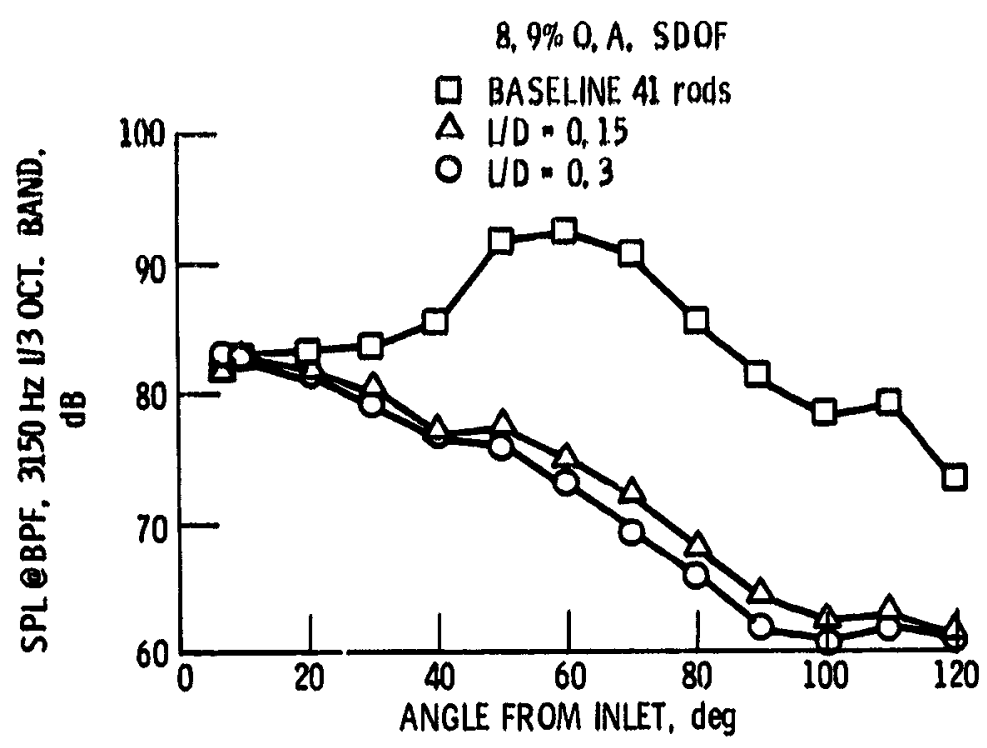

Figure 6. - Tone directivity pattern at the design point for hard walls and two liner lengths.

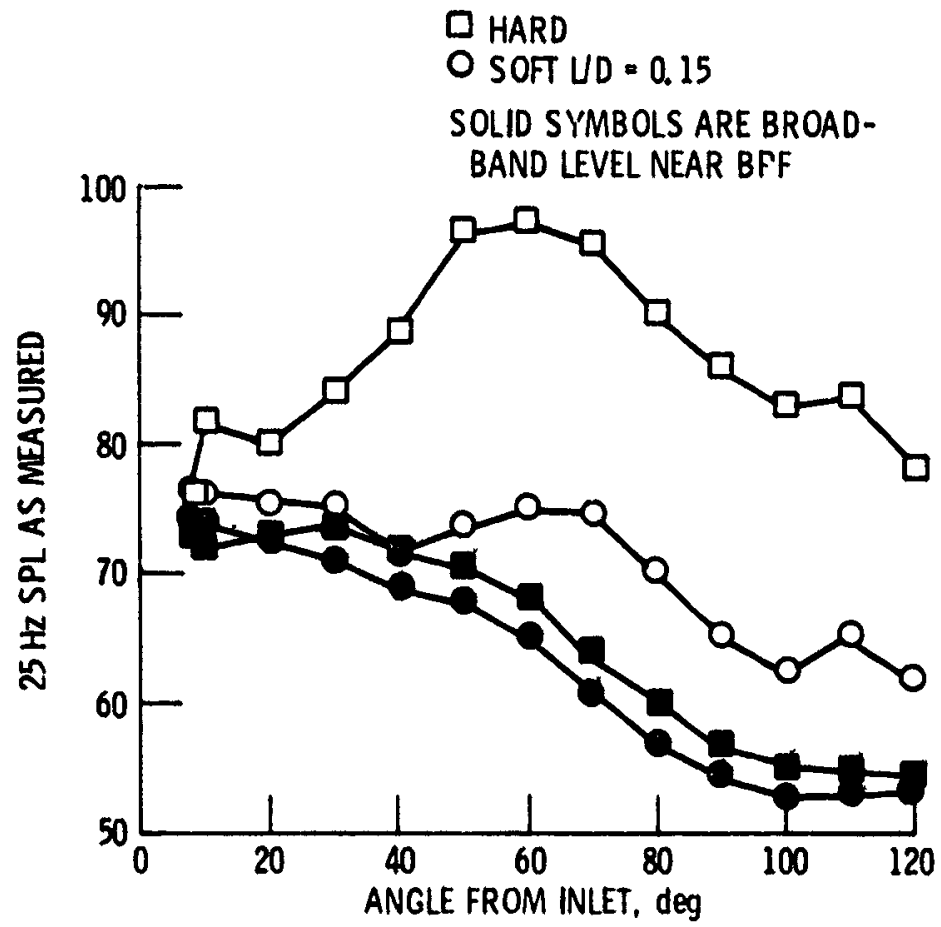

Figure 7. - Narrow band tone directivity pattern at the design point, BPF $=3150 \mathrm{~Hz}$ and $6750 \mathrm{rpm}$ for 89 percent open area liner. 


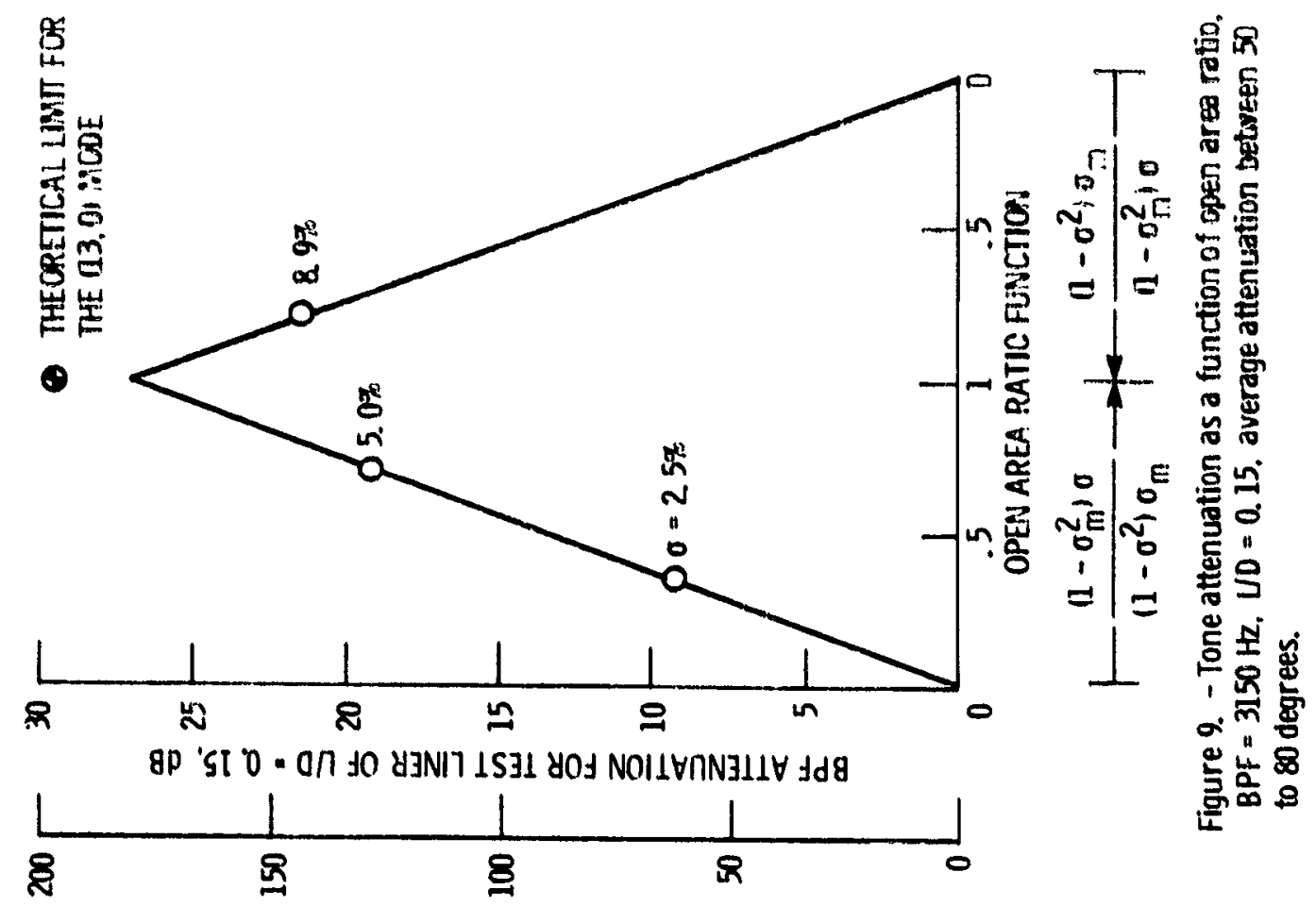

gp 'Oก IINก YOJ NOII

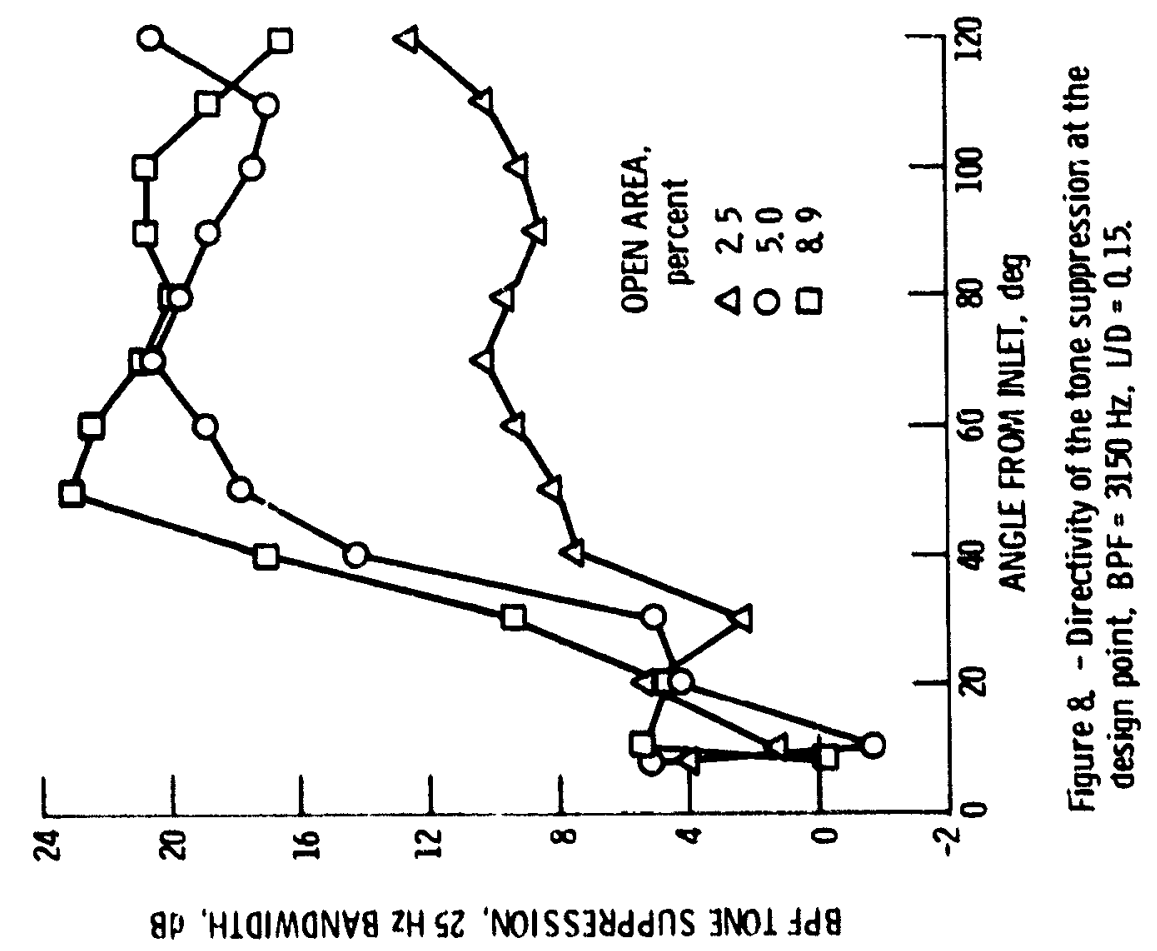



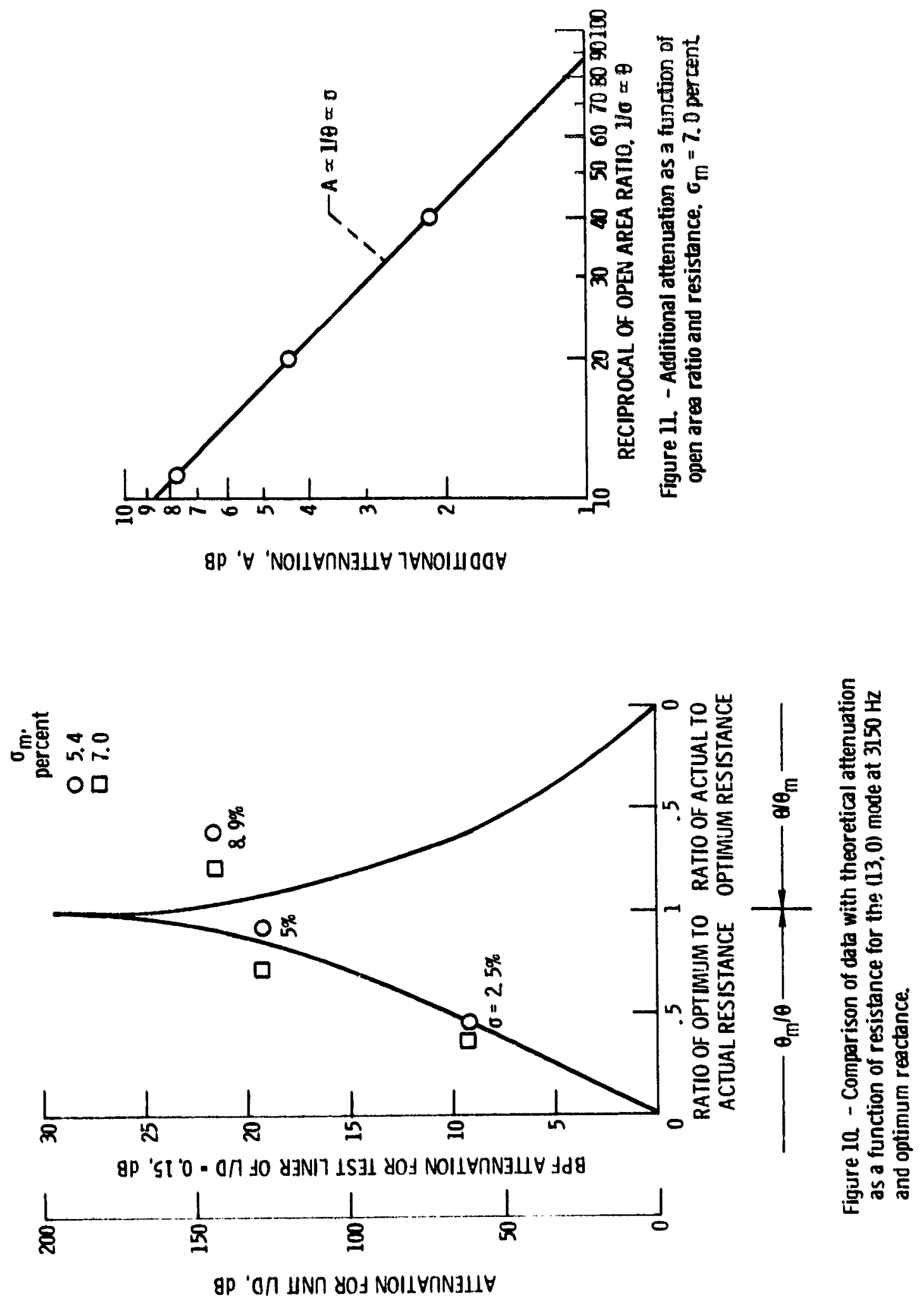


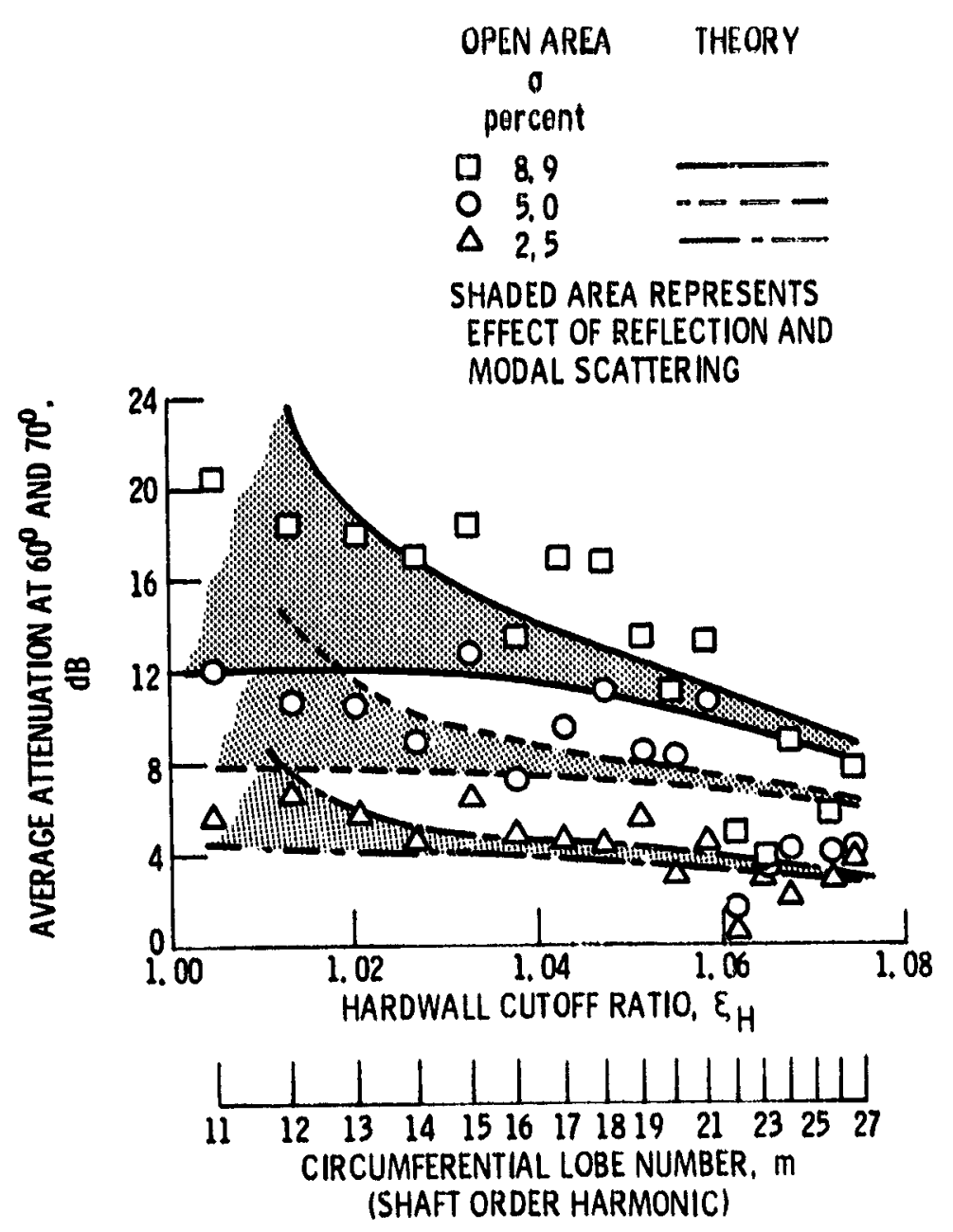

Figure 12. - MPT attenuation comparison with theory. 